\title{
ESTRATÉGIAS E PROCEDIMENTOS DE CRIANÇAS DO CICLO DE ALFABETIZAÇÃO FRENTE A SITUAÇÕES-PROBLEMAS QUE ENVOLVEM GEOMETRIA
}

\author{
STRATEGIES AND PROCEDURES OF LITERACY CICLE CHILDREN FRONT PROBLEM- \\ SITUATIONS INVOLVING GEOMETRY
}

ESTRATEGIAS Y PROCEDIMIENTOS PARA NIÑOS EN CLASSES DE ALFABETIZACIÓN CARA A SITUACIONES RELACIONADAS CON GEOMETRÍA

\author{
João Alberto da Silva ${ }^{1}$ \\ Karin Ritter Jelinek ${ }^{2}$ \\ Vinicius Carvalho Beck ${ }^{3}$
}

\begin{abstract}
RESUMO
O Ciclo de Alfabetização foi criado em 2010 e apresentou uma nova organização curricular para os anos iniciais do Ensino Fundamental. Ele tem demandado novas formas de ensinar e pensar a Matemática para crianças em fase inicial de escolarização. Empreendemos um esforço coletivo para pesquisar as estratégias e os procedimentos que os estudantes deste nível de ensino têm empreendido para enfrentar situações que envolvem conteúdos matemáticos determinados nas avaliações externas. Neste artigo contemplamos o estudo que trata especificamente das competências relativas à Geometria. Fundamentando-se na investigação-ação escolar e na ideia de situação-problema, propusemos diversas atividades aos estudantes a fim de investigar como procedem frente às habilidades previstas na Prova Brasil de Alfabetização Matemática. Os dados indicam dificuldades de estabelecer relação entre os espaços bidimensional e tridimensional no manejo das figuras geométricas, problemas oriundos de um ensino que privilegia figuras planas e noções espaciais ainda muito regidas por um pensamento egocêntrico.
\end{abstract}

PALAVRAS-CHAVE: Alfabetização Matemática. Geometria. Ciclo de Alfabetização.

\begin{abstract}
The Literacy Circle was established in 2010 and presented a new curricular organization for the early years of elementary school. He has sued new forms of teaching and thinking on Mathematics to children in early stages of schooling. Undertake a collective effort to research the strategies and procedures that students of this level of education have undertaken to address situations involving mathematical content determined in the external evaluations. In this article we contemplate the study that specifically addresses skills concerning geometry. Curran on research-action in school and the idea of situation-problem, we have proposed various activities to students in order to investigate how to proceed against the abilities set out in Brazil Literacy Math Proof. The data indicate difficulties to establish relationship between two-dimensional and three-dimensional spaces in the handling of geometric figures, problems arising from an education that focuses on flat and spatial figures still governed by an egocentric.
\end{abstract}

KEYWORDS: Math Literacy. Geometry. Literacy Cycle.

\footnotetext{
${ }^{1}$ Doutor em Educação pela Universidade Federal do Rio Grande do Sul, UFRGS, Porto Alegre, RS - Brasil. Professor da Universidade Federal do Rio Grande, FURG, Rio Grande, RS - Brasil. E-mail: joaosilva@ furg.br. ${ }^{2}$ Doutora em Educação pela Universidade Federal do Rio Grande do Sul, UFRGS, Porto Alegre, RS - Brasil. Professora da Universidade Federal do Rio Grande, FURG , RS - Brasil. E-mail: karinjelinek@ furg.br.

${ }^{3}$ Mestre em Educação pela Universidade Federal do Rio Grande, FURG, Rio Grande, RS. Professor do Instituto Federal Sul-rio-grandense, IFSUL-CAVG, Pelotas, RS - Brasil. E-mail: viniciusbeck@ifsul.cavg.edu.br. Recebido em: 08/06/2015 - Aceito em: 03/12/2015.
} 


\section{RESUMEN}

El ciclo de Alfabetización fue creado en 2010 y presentó una nueva organización curricular de los primeros años de la escuela primaria. Se ha requerido nuevas formas de enseñar y pensar las matemáticas a los niños en una etapa temprana de la escolaridad. Emprendemos un esfuerzo colectivo para investigar las estrategias y procedimientos que los alumnos de este nivel se han comprometido a abordar situaciones de contenido matemático determinado de evaluaciones externas. En este artículo se contempla el estudio que se ocupa específicamente de las habilidades relacionadas con la geometría. Basándose en la escuela de investigaciónacción y la idea de la situación problemática, propusimos diversas actividades para los estudiantes a investigar la forma de proceder en la cara de las competencias previstas en Brasil para examen de Matemáticas de la Alfabetización. Los datos indican dificultades para establecer relaciones entre los espacios bidimensionales y tridimensionales en la gestión de las figuras geométricas, los problemas derivados de una educación que se centra figuras planas y nociones espaciales aún mucho que se rigen por un pensamiento egocéntrico.

PALABRAS CLAVE: Matemáticas de alfabetización. Geometría. Ciclo de la Alfabetización.

\section{INTRODUÇÃO E QUALIFICAÇÃO DO PROBLEMA A SER ABORDADO}

A Matemática tem sido, em geral, uma das áreas que apresenta maiores índices de retenção de alunos nos anos iniciais do Ensino Fundamental. Também é nessa esfera que se ressaltam as chamadas dificuldades de aprendizagem, oriundas de problemas de raciocínio, concentração e motivação. Diversos estudos (BECKER, 2012; SILVA, 2010; CARRAHER, CARRAHER e SCHLIEMANN, 2006) têm mostrado que as práticas diretivas dominam o ensino da Matemática e produzem problemas na aprendizagem, por não permitirem o pensamento autônomo e criativo. Além disso, trata-se de uma área do conhecimento fundamental para a leitura de mundo do sujeito, bem como de interpretação de outros campos, como a Ciência, a História e a Engenharia. Nesse sentido, um domínio elementar da Matemática é fundamental para que qualquer estudante e cidadão, independentemente da profissão ou do lugar social que ocupe, interprete e interaja no mundo contemporâneo.

Ademais, a Resolução CNE no 7/2010 fixa novas Diretrizes Curriculares Nacionais para a Educação Básica e institui o Ciclo da Infância ou Ciclo de Alfabetização, compreendendo os três primeiros anos do Ensino Fundamental. Em muitos casos, equivocadamente, entendeu-se que a criação desse ciclo veio para reforçar o ensino apenas da leitura e da escrita da língua materna, resultando em uma orientação curricular menos comprometida com a Matemática. Somado a isso, nota-se que a nova organização causou um relativo estranhamento nas comunidades escolares, demandando maior investigação a respeito de sua estruturação e o desenvolvimento de novas metodologias de ensino da Matemática, buscando uma identidade própria para a etapa do ensino formal em questão.

Não obstante, as políticas públicas têm mobilizado diversos recursos para problematizar o espaço-tempo do ensino e da aprendizagem da Matemática com crianças, como, por exemplo, o Pró-Letramento, que empreende um conjunto de ações articuladas para a formação de professores dos anos iniciais no campo da Linguagem e da Matemática, a Prova e a Provinha Brasil de Matemática e, por fim, o Programa Nacional de Alfabetização na Idade Certa (PNAIC), que desenvolve temáticas voltadas para a Alfabetização Matemática. Essas diferentes ações e normatizações têm em comum uma concepção de aprendizagem centrada no desenvolvimento de habilidades e competências. 
Mais especificamente, a Provinha Brasil ${ }^{4}$ aplicada no Ciclo de Alfabetização, pauta-se em quatro eixos - Números e Operações, Grandezas e Medidas, Espaço e Forma, e Tratamento da Informação - os quais são oriundos dos blocos de conteúdos dos Parâmetros Curriculares Nacionais. Para cada um desses eixos, existe um conjunto de habilidades e competências definidas como essenciais para se considerar que a criança está alfabetizada no campo da Matemática.

Nesse sentido, realizamos um conjunto de pesquisas correlatas investigando o nível de desenvolvimento de crianças que estão finalizando e recém concluíram o Ciclo da Infância tomando por base as habilidades e competências previstas na Provinha Brasil de Matemática (SILVA, JELINEK, BECK, 2015; SILVA, CENCI, BECK, 2015; SILVA, JELINEK, BECK, MIRANDA, 2015). Neste artigo, abordaremos especificamente o estudo que tratou do segundo eixo da Matriz de Referência da Provinha ${ }^{5}$, que corresponde à área da Geometria. Assim, nosso objetivo foi realizar um mapeamento de como andam os níveis de Alfabetização Matemática do contexto estudado, no que se refere às habilidades relacionadas com o pensamento geométrico, bem como quais são as estratégias de resolução de problemas e modos de interpretar das crianças.

Trata-se de estudo exploratório cuja questão de pesquisa a busca a compreensão de como os alunos resolvem situações-problema que demandam recursos ligados às competências e habilidades exigidas na Provinha no campo da Geometria. A competência é identificada pelo código $\mathrm{C} 4 \mathrm{e}$ descrita como Reconhecer as representações de figuras geométricas. Dois descritores (D4.1 e D4.2) indicam as habilidades envolvidas, quais sejam: (D4.1) Identificar figuras geométricas planas e (D4.2) Reconhecer as representações de figuras geométricas espaciais. Assim, a partir da proposição de tal competência e dos dois descritores, foram apresentadas situações-problemas às crianças com o objetivo de investigar os modos, procedimentos e estratégias empregados por elas na resolução das tarefas propostas.

\section{A GÊNESE DO ESPAÇO NA CRIANÇA}

A revisão da literatura aponta uma produção relativamente grande sobre o ensino de geometria para crianças (NACARATO e PASSOS, 2003; LAMONATO e PASSOS, 2009; PAIS, 2010; entre outros), mas bastante escassa no que se refere ao Ciclo de Alfabetização ou à avaliação externa. Acreditamos que isso se deve pelo ineditismo dessas duas políticas públicas. Em especial, encontramos um único trabalho no qual há uma discussão pormenorizada do eixo referente à Geometria na Provinha Brasil de Matemática. (PASSOS e NACARATO, 2014). As autoras analisam as habilidades requeridas na Matriz de Referência e os itens apresentados nas últimas edições da Provinha. As análises apontam alguns problemas matemáticos nas elaborações dos itens, principalmente, nas imagens utilizadas como suporte. Indicam itens nos quais há confusão entre círculo, circunferência ou coroa

\footnotetext{
${ }^{4}$ A Provinha Brasil ou Prova Brasil de Alfabetização Matemática é uma avaliação anual do Governo Federal que começou a ser aplicada em 2008. Em 2011, o Inep criou a provinha de matemática, buscando complementar a avaliação já existente na área da leitura e letramento. Desde 2012, as duas provas são aplicadas no início e no fim de cada ano letivo.

${ }^{5}$ Não se trata de assumir esse instrumento de avaliação externa como um referencial curricular do que deveria ser ensinado ou considerado parâmetro do bom ensino. A Provinha é utilizada como uma amostragem dos principais pontos que deveriam ser ensinados no Ciclo de Alfabetização nos campos de conhecimento da Matemática. É nestes termos que ela é utilizada: como um indicador de competências e habilidades que permite uma visão, ainda que parcial, de uma efetiva Alfabetização Matemática.
} 
circular; contextos que podem confundir o estudante e imagens inapropriadas para representar determinadas figuras. Também destacam as limitações dos itens para este tipo de avaliação externa, mas consideram importante a abordagem feita à Geometria e apropriados os descritores para avaliar as habilidades de crianças ao final do segundo ano de escolarização.

Em termos teóricos, os diferentes estudos revisados possuem um referencial ligados à cognição e aos processos de pensamento. Assim, o referencial que assumimos para discutir o tema da geometria no Ciclo de Alfabetização se alinha as abordagens presentes na literatura, que é o viés dos estudos construtivistas, principalmente, aqueles oriundos das pesquisas de Jean Piaget e Barbel Inhelder (1993) a respeito da construção do espaço pela criança. Estes autores e os conjuntos de pesquisas posteriores (ALMOULOUD; MANRIQUE; GOUVEA, 2002; ALMOULOUD; MANRIQUE; SILVA; CAMPOS, 2004; OLIVEIRA, 2005) que se desenvolveram a partir desse estudo pioneiro defendem a ideia de que o espaço geométrico é uma construção humana e se organiza de diferentes maneiras ao longo da vida em função do desenvolvimento cognitivo e das experiências singulares de cada sujeito. Entende-se que essa vertente teórica é uma das que mais influencia os Parâmetros Curriculares Nacionais (BRASIL, 1997) e seus desdobramentos, tais como é o caso da Matriz de Referência da Provinha Brasil de Matemática.

Ao se pensar a ideia do espaço, é fundamental compreender que este se articula com a própria noção do sujeito sobre sua localização e capacidade de representação do lugar que ocupa. Assim, Piaget (1994) chama atenção para uma característica do pensamento infantil, que é o egocentrismo, isto é, a dificuldade de se colocar em outro ponto de vista que não o seu próprio. De modo complementar, a descentração corresponde ao processo de distinguir o outro e seus próprios pontos de vista, tanto em relação a pessoas quanto a objetos ou figuras. Nesses termos, a noção de espaço na criança é fortemente influenciada pelo egocentrismo, que dificulta a coordenação dos diferentes pontos de vista dos elementos espaciais e dos próprios objetos ou figuras individualmente, pois são percebidos, em grande parte, a partir do ponto de vista exclusivo do observador.

Em relação as noções espaciais propriamente ditas, pode-se dizer que a noção de espaço da criança e sua compreensão sobre figuras geométricas se estrutura de três maneiras, com base nas relações topológicas, projetivas ou euclidianas (PIAGET; INHELDER, 1993). $\mathrm{O}$ espaço topológico é o mais elementar e refere-se às primeiras relações que as crianças constroem. No plano da representação significa reconhecer e representar graficamente as relações topológicas de vizinhança, separação, ordem, contorno e continuidade. Assim, os sujeitos podem distinguir entre figuras fechadas e abertas e caracterizar o interior e o exterior de uma forma geométrica. De fato, trata-se da constituição do objeto singular e de seu espaço próximo nas suas primeiras relações constituidoras.

O espaço projetivo já é uma forma de compreensão mais sofisticada e implica maior descentração do ponto de vista do observador. Esta forma de lidar com o espaço envolve uma maior coordenação de perspectivas, de estruturação das grandezas e de formas aparentes. $\mathrm{O}$ maior destaque se dá para o fato de que os objetos não são mais percebidos isoladamente, mas em uma situação de conjunto. O desenho da criança nesse momento, por exemplo, apresenta suas diferentes figuras de modo articulado e relacionadas entre si.

O espaço euclidiano é o que possibilita a organização tridimensional das relações espaciais e figurativas. Ele implica o estabelecimento de um sistema de coordenadas para

\begin{tabular}{l|l|l|l|l|l|l} 
(C) ETD -Educ. Temat. Digit. & Campinas, SP & v.18 & n.2 & p.313-331 & abr./jun.2016 & ISSN 1676-2592
\end{tabular}


localização das formas no espaço limitado, o que permite uma matematização do espaço e a manipulação das figuras levando valores numéricos e algébricos.

\section{METODOLOGIA}

O presente artigo é fruto de um projeto mais amplo (SILVA, JELINEK, BECK, 2015; SILVA, CENCI, BECK, 2015; SILVA, JELINEK, BECK, MIRANDA, 2015), que envolve uma análise, sob diferentes aspectos, do ensino e da aprendizagem da Matemática nos Ciclo de Alfabetização. Outros estudos de caráter complementar foram desenvolvidos concomitantemente a fim de se constituir uma ação conjunta, inspirada e adaptada a partir das metodologias de pesquisa em consórcio (SILVA, MARINHO e FRANÇA, 2013). Em termos gerais, trata-se da realização de uma investigação coletiva, com diversos temas correlatos, no campo da Alfabetização Matemática. Outros estudos em vias de conclusão, no âmbito desse consórcio, abordam diferentes habilidades e competências relativas à Alfabetização Matemática a fim de que juntos possam constituir um mapeamento mais geral do que ocorre no Ciclo da Infância tomando por referência as habilidades previstas na Provinha Brasil de Alfabetização Matemática. As vantagens dessa modalidade conjunta são a possibilidade de se contar com múltiplos olhares sobre o mesmo caso, enfoques sob diferentes aspectos, reflexão coletiva e cooperativa na coleta e análise de dados, bem como o entrecruzamento surgido das diferentes temáticas similares investigadas.

\section{a) Delineamento}

Este estudo teve seu referencial metodológico ligado à interpretação, compreensão e aprofundamento de um contexto educativo escolar em um nível de ensino específico, o que produz um maior grau de complexidade para a questão de pesquisa. No contexto dos estudos qualitativos, esta proposta inspirou-se, mais especificamente, na pesquisa participante do tipo investigação-ação escolar. Para Carr e Kemmis (1988), a investigação-ação difere-se da pesquisa-ação e configura-se como uma pesquisa participante, pois oferece uma oportunidade de articulação entre teoria e prática, que promove a emancipação dos sujeitos envolvidos, através da interlocução, em que todos são participantes.

A investigação-ação escolar é constituída pelos ciclos de planejamento, ação, observação e reflexão (CARR; KEMMIS, 1988), em progressivos níveis de complexidade. A etapa de planejamento consiste na organização antecipada da ação, ou seja, são discutidos os rumos da investigação. As atividades didáticas foram construídas a partir da perspectiva dos professores, levando-se em conta o contexto da sala de aula e o referencial teórico, de modo que fosse possível detectar como as crianças se relacionam com as competências necessárias para agir na situação proposta. $\mathrm{Na}$ segunda etapa, ou seja, a ação, implementou-se as atividades planejadas diretamente com os estudantes.

A observação, terceiro momento, tem a função de documentar as decorrências da ação, ou seja, "observar o processo da ação, os efeitos da ação, as circunstâncias da ação e suas limitações, o modo em que as circunstâncias e as limitações recortam e canalizam a ação planejada e seus efeitos e outras coisas que podem surgir" (KEMMIS; MACTAGGART, 1988 , p. 19). Os registros foram realizados em diários adotados pelos investigadores (em média dois pesquisadores por sala de aula, mais o professor-regente) durante e após os encontros. Dada a necessidade de ação e observação simultâneas, a cooperação e o envolvimento efetivo do professor-regente da turma é fundamental para que a atividade não adquira ares muito diferenciados do contexto escolar habitual e cause estranhamento nas 
crianças, bem como para que se permita, que durante a condução das atividades outros possam dedicar-se apenas a observar com atenção. Nesse sentido, o professor-regente da turma integra o grupo de pesquisas e participa de todo o processo de desenho, investigação e análise do estudo.

No quarto momento, a reflexão, ponderamos e avaliamos os processos tanto individuais quanto coletivos da investigação-ação escolar. Nesse procedimento, o foco central das reflexões são as práticas educativas, os resultados obtidos e o entendimento dos participantes a respeito delas. Através do diálogo, podemos compartilhar situações comuns, levantar contradições e situações-problema, compreendendo as situações.

Os quatro momentos citados são dinâmicos e compõem o que se tem chamado de ciclos da espiral de investigação-ação escolar (KEMMIS; MACTAGGART, 1988), que se constituem retrospectiva e prospectivamente. No caso específico desta pesquisa, as etapas da investigação-ação escolar estruturam-se da seguinte maneira:

Quadro 1 - Detalhamento da investigação-ação realizada

\begin{tabular}{|l|l|}
\hline Momentos & \multicolumn{1}{|c|}{ Descrição } \\
\hline Planejamento & $\begin{array}{l}\text { Estudo da realidade da proposta. Desenvolvimento da compreensão sobre as competências e } \\
\text { habilidades em estudo. Construção da situação-problema. Elaboração dos materiais a serem } \\
\text { aplicados. }\end{array}$ \\
\hline Ação & $\begin{array}{l}\text { Ação nas turmas do } 3^{\text {o }} \text { ano para coleta de informação. Proposição das atividades. } \\
\text { Elaboração de perguntas durante o desenvolvimento das estratégias pelas crianças. }\end{array}$ \\
\hline Observação & $\begin{array}{l}\text { Observação das condutas das crianças, dos materiais que produziram e das explicações } \\
\text { que adotaram para algumas estratégias. }\end{array}$ \\
\hline Reflexão & $\begin{array}{l}\text { Análise dos dados coletados. Reflexão sobre os limites da situação-problema empregada. } \\
\text { Elaboração de uma compreensão de como as crianças do Ciclo da Infância agem e as } \\
\text { capacidades que apresentam no campo da Geometria. }\end{array}$ \\
\hline
\end{tabular}

Fonte: Os autores

\section{b) Campo de estudo e participantes da pesquisa}

A partir da ideia de se investigar as estratégias de resolução, os modos de entendimento e os procedimentos dos estudantes do Ciclo de Alfabetização, entende-se que tal nível de ensino se propõe a desenvolver seus objetivos ao longo de todo o processo, mas com relativa garantia de atingi-los plenamente apenas ao final do Ciclo. Assim, entendemos que é interessante investigar os sujeitos que estão concluindo a referida etapa, isto é, os alunos no final do $3^{\circ}$ ano.

Participaram duas turmas do ensino regular da rede pública municipal de uma cidade do interior do Rio Grande do Sul, com quinze e dezoito alunos, o que totaliza 33 sujeitos participantes da pesquisa. Eram atendidas por duas professoras com nível superior, que integravam o grupo de pesquisas no qual este estudo foi desenvolvido. Elas conduziram e apoiaram o desenvolvimento da coleta de dados, o que evitou um maior estranhamento dos estudantes com a presença dos pesquisadores e da condução de uma atividade diferenciada. Os critérios de escolha desses grupos de alunos foram a disponibilidade e a possibilidade, bem como o diferencial de que suas professoras-regentes integravam a equipe de investigação.

De fato, o objetivo não foi o de estabelecer comparações entre os dois grupos. Sendo

\begin{tabular}{l|l|l|l|l|l|l} 
(C) ETD -Educ. Temat. Digit. & Campinas, SP & v.18 & n.2 & p.313-331 & abr./jun.2016 & ISSN 1676-2592
\end{tabular}


assim, os dados não serão apresentados evidenciando diferenças entre sujeitos de uma turma e de outra. Além disso, não houve expectativa de uma avaliação individual de desempenho, com vistas a observar quais os estudantes resolveram os problemas propostos. Entendemos que essa função de averiguação é desempenhada pela própria Prova Brasil e pela Provinha Brasil de Matemática e que seus dados quantitativos são mais confiáveis para a questão. Nosso foco foi dirigido à observação dos dados qualitativos, sem nos preocuparmos se uma criança pedia ajuda a outra ou se trocavam informações durante o desenvolvimento da tarefa.

\section{c) A construção dos procedimentos de coleta de dados}

Dentro da perspectiva da investigação-ação escolar, durante a etapa do planejamento, diversos foram os movimentos de estruturação da situação-problema a ser desenvolvida com os estudantes. Nesse momento, os pesquisadores e os professores da educação básica organizaram-se de forma a criar situações didáticas não muito diferenciadas do contexto escolar, mas focadas em demandas relativas às competências e habilidades em questão.

Dentro do contexto das pedagogias ditas tradicionais, os conteúdos são entendidos como um conjunto de informações que deve ser disponibilizado pelo professor ao aluno (BECKER, 2012; SILVA, 2010). Os modos de aprender e ensinar, a partir dessa ideia, voltam-se à memorização das informações e à transmissão dos conhecimentos pela via sensorial. Por outro lado, as práticas pedagógicas contemporâneas e os diversos estudos no campo dos fundamentos da educação têm questionado tal abordagem e a função de retenção das informações. Partindo dessa problematização, a didática atual tem se ocupado em criar modelos pedagógicos e referenciais curriculares que se sustentam nos conteúdos matemáticos, mas se direcionam para ideias de habilidades e competências que articulem estes conteúdos, em oposição à perspectiva de informações e conceitos memorizados e automatizados.

Adquirir conteúdos e informações é um passo importante dos processos de aprendizagem, mas não suficiente, haja vista a importância de saber o que fazer, interpretar os dados e mobilizar os conceitos nas situações e problemas que enfrentamos. Assim, Perrenoud (2000) define que competência é a capacidade de agir eficazmente nas situações, mobilizando os recursos disponíveis, sejam materiais, afetivos ou cognitivos. No mesmo sentido, as habilidades configuram-se como o conjunto de conhecimentos práticos voltados a um saber-fazer e ao desenvolvimento de procedimentos. Elas ampliam as ideias dos conteúdos, que, usualmente, adquirem um fundo mais informacional, sem se ocupar das aprendizagens dos saberes procedimentais e atitudinais (ZABALA, 2000).

Como estratégia didática e de desenvolvimento de habilidades e competências, temos pensado na ideia de situação-problema. Elas se caracterizam por recortes de um domínio complexo, cuja realização implica saber usar recursos materiais e cognitivos, tomar decisões e mobilizar estratégias de solução de problemas (PERRENOUD, 2000). Na mesma direção, segundo Meirieu (1998), as situações-problema apresentam-se como uma circunstância didática que demanda ao estudante uma tarefa que ele não pode realizar sem aprender alguma coisa. Em outras palavras, a situação-problema é uma estratégia que visa desenvolver uma capacidade e não apenas a verificação da acumulação dos conteúdos. Através dela podemos evidenciar as habilidades e as competências que as crianças possuem, bem como sua capacidade de aprender e reagir frente a situações com as quais não haviam mantido contato.

A propósito dos elementos que compõem e caracterizam uma situação-problema, temos trabalhado sobretudo com aqueles indicados por Perrenoud (2000), Macedo (2002), 
Meirieu (1998) e Zabala (2000), que incluem o contexto significativo da situação, o obstáculo a ser enfrentado, o caráter de desafio da situação, os saberes prévios que os estudantes precisam possuir, as aprendizagens que podem desenvolver, as resistências que tendem a encontrar na resolução das tarefas e as possibilidades de validação das estratégias que utilizaram.

Nesse sentido, a ação, segundo passo da investigação-ação escolar, direcionou-se para uma situação-problema que demandou a mobilização da capacidade de identificar figuras planas e de reconhecer figuras espaciais, envolvendo o contexto dos estudantes. Inicialmente, foram retomados em sala de aula os desenhos dos polígonos, a fim de evidenciar o seu uso na investigação e verificar o domínio que os estudantes possuíam do vocabulário mais formal. Foram desenhadas algumas figuras planas no quadro-negro e solicitado que as crianças informassem os nomes. Depois, elas mesmas disseram nomes de figuras e pediram que a professora desenhasse no quadro.

Posteriormente, o grupo foi levado para a frente da escola, onde foi requisitado que, usando as figuras planas, desenhassem a fachada da escola ${ }^{6}$ a partir do ponto de vista em que estavam. Enquanto realizavam os desenhos, o grupo de investigadores acompanhava as crianças e inquiria a respeito de algumas formas de traçado que iam aparecendo.

Depois de confeccionado esse croqui, as crianças retornaram ao ambiente da sala de aula e, a partir de materiais recicláveis anteriormente requisitados, foi pedido que construíssem, em pequenos grupos, uma maquete da escola. A turma esteve livre para se organizar e formular estratégias com o intuito de alcançar o desafio da atividade. Novamente, enquanto faziam suas escolhas e negociavam no grupo a melhor maneira de confeccionar o empreendimento, os pesquisadores acompanhavam as crianças, realizando perguntas. Os dados obtidos foram registrados no caderno de campo. Foram realizadas ainda fotografias das maquetes e cópias dos desenhos da fachada da escola.

Por fim, entendemos que tal atividade configura-se como uma situação-problema, na medida em que requer dos estudantes a solução de uma conjuntura e apresenta as características do quadro a seguir.

\footnotetext{
6 Evidente que seria mais fácil para o leitor compreender o contexto e os desenhos das crianças se apresentássemos uma foto da fachada da escola. Assim, seria possível ver de onde os estudantes retiraram informações para suas representações. Todavia, tal ação identificaria a instituição, o que não nos é permitido ou aconselhado, com vistas à manutenção dos princípios éticos de sigilo e anonimato dos sujeitos envolvidos.
} 
Quadro 2 - Detalhamento da situação-problema

\begin{tabular}{|c|c|}
\hline $\begin{array}{l}\text { SITUAÇÃO } \\
\text { PROBLEMA }\end{array}$ & $\begin{array}{l}\text { Projetar e construir duas representações, uma bi e outra tridimensional sobre uma } \\
\text { mesma imagem do cotidiano. A demanda indicava que o desenho bidimensional } \\
\text { deveria ser feito com figuras geométricas planas. Para a maquete, foi requisitado } \\
\text { que usassem materiais recicláveis que possuem a forma de poliedros para } \\
\text { representar a imagem. }\end{array}$ \\
\hline OBSTÁCULO & $\begin{array}{l}\text { O obstáculo está em identificar as figuras planas que podem representar uma } \\
\text { imagem do cotidiano em um desenho bidimensional, bem como construir uma } \\
\text { maquete usando materiais recicláveis com a forma de poliedros que representem } \\
\text { a mesma imagem. }\end{array}$ \\
\hline DESAFIO & $\begin{array}{l}\text { Estabelecer relações entre figuras planas a fim de constituírem um desenho que } \\
\text { represente a fachada da escola, bem como utilizar materiais recicláveis com a } \\
\text { forma de poliedros para representar a escola em uma maquete. }\end{array}$ \\
\hline SABERES & $\begin{array}{l}\text { Nomenclatura das figuras geométricas planas e espaciais. Conhecimento dos } \\
\text { diferentes tipos de figuras e suas propriedades. Desenho bidimensional e } \\
\text { construção de maquetes. }\end{array}$ \\
\hline APRENDIZAGENS & $\begin{array}{l}\text { Aprender a estabelecer relações entre imagens do cotidiano e representações } \\
\text { bidimensionais e tridimensionais. Construir desenhos bidimensionais a partir da } \\
\text { observação. Aprender a reconhecer poliedros que podem representar espaços } \\
\text { cotidianos. }\end{array}$ \\
\hline RESISTÊNCIA & $\begin{array}{l}\text { Os diferentes pontos de vista que se pode ter ao observar a imagem. As } \\
\text { referências anteriores que as crianças têm sobre o desenho e o local que devem } \\
\text { representar. A dificuldade em representar com figuras planas uma imagem que é } \\
\text { tridimensional. }\end{array}$ \\
\hline VALIDAÇÃO & $\begin{array}{l}\text { Observação da fachada com o desenho realizado. Identificação da maquete com } \\
\text { o prédio e o desenho bidimensional. }\end{array}$ \\
\hline
\end{tabular}

Fonte: Os autores

Durante o desenvolvimento e a aplicação dessa situação-problema, os pesquisadores registraram em seus cadernos de campo os comportamentos das crianças, as falas que justificavam e explicavam as estratégias por eles adotadas e os produtos do trabalho que realizaram. As informações coletadas constituíram-se nas principais fontes de dados, os quais são analisados a seguir.

\section{ANÁLISE E DISCUSSÃO DOS DADOS COLETADOS}

Os dados obtidos através do desenvolvimento desta investigação-ação escolar são relevantes para que possamos analisar as estratégias que as crianças utilizaram para resolverem a situação-problema que lhes foi proposta. Eles foram organizados de maneira a elucidar os modos de proceder dos estudantes, em função das habilidades envolvidas, o que remete à existência de duas categorias de análise: uma para cada um dos descritores que envolvem a competência em questão. 


\section{a) D4.1 Identificar figuras geométricas planas}

Identificar figuras engloba um conjunto de capacidades e processos de raciocínio. Pode parecer, inicialmente, que se trata de um conhecimento elementar, dependente apenas da observação atenta. De fato, envolve a atenção em observar a figura, mas, sobretudo, implica conhecer a linguagem apropriada, examinar as propriedades de cada imagem e associá-las, a fim de se elaborar a inferência correta.

Quanto à capacidade de nomear as figuras planas, os alunos não demonstraram dificuldade, pois a cada questionamento sobre qual figura estava sendo desenhada, a resposta era dada rapidamente e sem dificuldade. Isso pode ser evidenciado a partir da seguinte observação:

A professora começa a desenhar figuras planas no quadro-negro e pergunta quais delas as crianças lembram. Ela desenha um quadrado e um aluno responde de forma rápida e correta:

- Esse é um quadrado!

Logo após responder, já indica o nome de outra figura (círculo) para que esta seja desenhada pela professora.

- E tem também o retângulo.

A professora realiza o desenho do retângulo no quadro. Os alunos continuam atentos aos diferentes desenhos que eram feitos no quadro e continuam nomeando as imagens. (Anotações de campo, pesquisador $\mathrm{G}$ ).

Nota-se que existe uma facilidade de identificar as representações gráficas das figuras planas, mas, por vezes, há problemas em nomear corretamente o desenho. É muito comum o uso de termos não convencionais no dia a dia, como o "retângulo cortado" para se identificar o triângulo ou o "quadrado torto" para falar do losango. Não se tem a intenção de que os modos de falar do cotidiano sejam invalidados ou classificados como de menor valia, mas é importante que o estudante amplie seu repertório lexical, a fim de que possa compreender situações de maneira mais formal. Além disso, mais do que diferenciar as figuras, identificar implica também saber usar o nome correto, haja vista que, no uso social, é necessário entender e fazer-se compreender na linguagem. Nota-se, também, traços de um pensamento egocêntrico (PIAGET, 1994), pois algumas figuras, que são menos familiares, são identificadas como partes de outras e suas diferenças são negligenciadas ou reduzidas de importância para implicar uma figura diferente daquela que imaginam.

Uma das confusões mais usuais refere-se ao círculo, circunferência e outras formas arredondadas, todas reduzidas à nomenclatura de bola, bolota ou redondo. $\mathrm{O}$ relato a seguir mostra como os estudantes estão habituados a termos menos formais ou, algumas vezes, equivocados: 
Há no quadro-negro o desenho de um quadrado, um retângulo, um triângulo, um círculo e um trapézio-retângulo. Os estudantes começam a conversar entre si:

- Aquele primeiro é um quadrado, depois tem um quadrado espichado.

Outro colega complementa:

- Depois é o triângulo, a bola e um retângulo com um pedacinho quebrado.

(Anotações de campo, pesquisador B).

Seria possível imaginar que este estudante, ao nomear o retângulo como um quadrado, não domina a diferenciação dos polígonos pela medida dos lados e sua forma, isto é, estaria desconsiderando uma das propriedades mais importantes para a classificação das figuras planas. Entretanto, a partir das falas observadas, é possível ver que, muitas vezes, o retângulo é reduzido à ideia de um quadrado com alguma característica especial, como ser "espichado", significando que nem todos os lados são iguais. Evidentemente que o aluno em questão não domina por completo a habilidade de identificar figuras, mas é importante salientar que ele já diferencia as imagens, ao destacar que a segunda representação possui um detalhe particular. Falta-lhe o domínio do termo correto, mas o retângulo não é simplesmente reduzido ao quadrado - muito embora a recíproca seja verdadeira - haja vista que, ao termo coloquial, é atribuída uma característica para diferenciá-lo.

Assim, pode-se observar uma das estratégias utilizadas quando o estudante desconhece o nome: ele se sustenta em uma outra figura que conhece e adiciona um detalhe que classifica aquele polígono desconhecido como uma variante da figura a qual sabe nomear. O mesmo acontece ao falar do trapézio: este é identificado como um retângulo com um corte na lateral, ou seja, o retângulo é a figura conhecida e a imagem que não se sabe nomear é agrupada, por semelhança, em tal categoria, mas acrescida de uma descrição particular. Nota-se que nesta estratégia há o que Piaget e Szeminska (1981) chamam um jogo de classificações, que vai organizando as figuras e suas denominações. De acordo com os autores, a estrutura de classe é uma organização lógico-matemática que permite classificar o objeto levando em conta suas semelhanças. Dessa maneira, a criança se vale da estrutura lógica das classes para incluir ou excluir uma figura em determinada designação e articula suas especificidades em subclasses que classificam de modo mais específico as variações.

Ainda referente à identificação de figuras planas, foi investigada a capacidade dos estudantes de identificarem os polígonos existentes em faces de poliedros ao observarem uma imagem do cotidiano. No caso explorado, a vista frontal da instituição é bastante simples, sendo um prédio único com a fachada em formato retangular (Figura 1a). Existem alguns outros elementos menores, tais como árvores, uma caixa-d'água e lixeiras. Em geral, as crianças utilizaram-se de quadriláteros para desenhar a fachada, as portas e as janelas. Por vezes, usaram retângulos para desenhar algum arabesco ou outro detalhe.

Em uma das escolas, diferentemente, a caixa d'água do prédio acabou tornando-se um objeto controverso. Ela é um grande cilindro apoiado em um alicerce em forma de prisma, de base triangular. Do ponto de vista dos estudantes, na altura da rua, a caixa-d'água não permite visualizar as mencionadas bases em formato de círculo ou triângulo. No caso do alicerce em forma de prisma de base triangular, a face exposta e aparente para as crianças é um retângulo. Todavia, em muitos desenhos realizados, tal elemento não foi referendado através de um quadrilátero. Muitos se atrapalharam nos desenhos e deixaram-se confundir pela possível vista superior, ainda que não ela não estivesse acessível (Figura 1b).

O fato da vista superior influenciar as representações é recorrente em muitos desenhos. Por ocasião do desenho da fachada do prédio, a instrução fornecida foi de que 
desenhassem estritamente o que estavam vendo com o uso de figuras planas. Ainda que houvesse a solicitação, muitos estudantes não desenharam o que estavam vendo, pois fizeram um traçado considerando uma vista superior (Figura 1c).
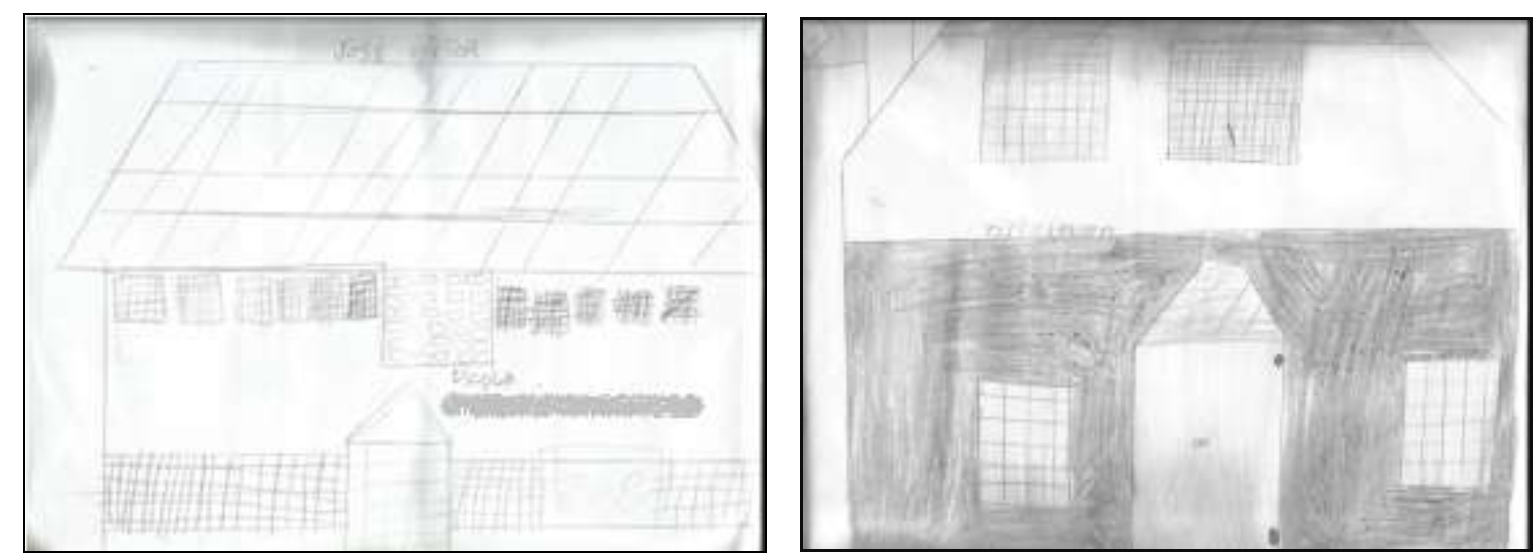

(a) Desenhos das fachadas das escolas, utilizando, sobretudo, quadriláteros

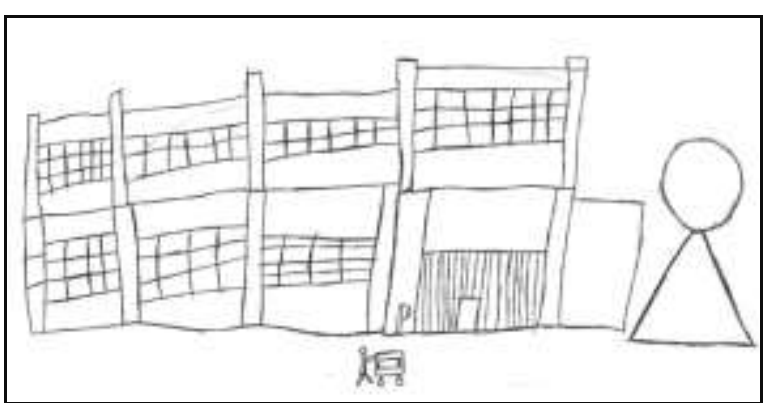

(b) Desenho da fachada da escola com a caixa d'água à direita

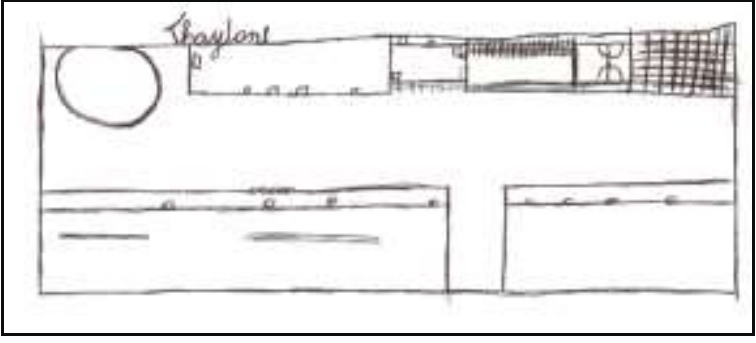

(c) Desenho da criança para a fachada do prédio, representada por uma vista superior da instituição

FIGURA 1 - Imagens de desenhos das crianças com pontos de vista referenciados Fonte: Pesquisa de campo

Em termos de relações espaciais, é interessante notar que é possível encontrar procedimentos que se alicerçam, sobretudo, em relações projetivas (PIAGET; INHELDER, 1993), como uma projeção ortogonal. Mesmo dispondo do objeto físico e da imagem sensorial diante dos olhos, a representação que as crianças constroem desse espaço procura expressar mais relações. O espaço euclidiano, com suas dimensões de ângulos e medidas, ainda que mais formal e adequado, não é suficiente para expressar essas diferentes experiências e informações que as crianças possuem, tal como saber que a imagem superior da caixa d'água possui a forma de um círculo ou que sua base possui a forma de um triângulo. Dessa forma, os estudantes recorrem a elementos projetivos a fim de conseguir expressar no desenho tudo o que compreendem como importante.

Assim, de maneira geral, percebemos que os objetos cujas faces são semelhantes, isto é, compostas por quadriláteros, não apresentam obstáculos para a representação das crianças. Diferentemente, torna-se um fator de dificuldade a existência de polígonos de natureza distintas nas faces de um mesmo poliedro, pois o estudante não sabe como representar a 
situação. Nesse caso, o ponto de vista e a perspectiva do desenho passam a ser objeto de atenção e produzem modos diferentes de desenhar, como é o caso da caixa d'água e de outros objetos.

\section{b) D4.2 Reconhecer as representações de figuras geométricas espaciais}

No caso das figuras espaciais, as dificuldades foram um pouco maiores. Trata-se de um dado interessante, pois ainda que as crianças estejam mais habituadas a interagir com objetos tridimensionais do que com figuras planas, possuem muita dificuldade para representá-los. Ainda que, de acordo com Piaget e Inhelder (1993), a construção da noção espacial se estrutura primeiramente em suas relações topológicas para depois organizar-se no espaço projetivo e euclidiano. Em outras palavras, os participantes estão relativamente acostumados ao manejo do espaço e de suas relações, mas as representações, sejam projetivas ou euclidianas, demandam uma construção mais sofisticada do que o manejo diário pode fornecer.

Além disso, supomos que o conhecimento escolar pode ter influenciado na realização da tarefa haja vista que a geometria plana é a primeira a ser introduzida, os objetos tridimensionais são muito pouco trabalhados, e os estudantes têm a expectativa de fornecer as respostas que imaginam ser as esperadas pelo professor. No caso específico dessa habilidade, tem-se a expectativa de que o aluno possa reconhecer as figuras, saber nomeá-las e relacionar imagens cotidianas com os poliedros representados usualmente. A atividade da maquete teve a intenção de que, a partir da observação realizada, do desenho confeccionado e das próprias experiências em passear pela escola, fosse projetada uma representação tridimensional da instituição.

Uma característica muito peculiar foi encontrada na execução da tarefa, que é novamente a influência do ponto de vista superior. No caso da tridimensionalidade e da construção de uma maquete, esse fator não deveria ter tanta influência, pois é possível observar o material reciclável usado na confecção sob diferentes pontos de vista. Os dados a seguir ilustram essa situação. A imagem é uma maquete construída por um grupo de três crianças.

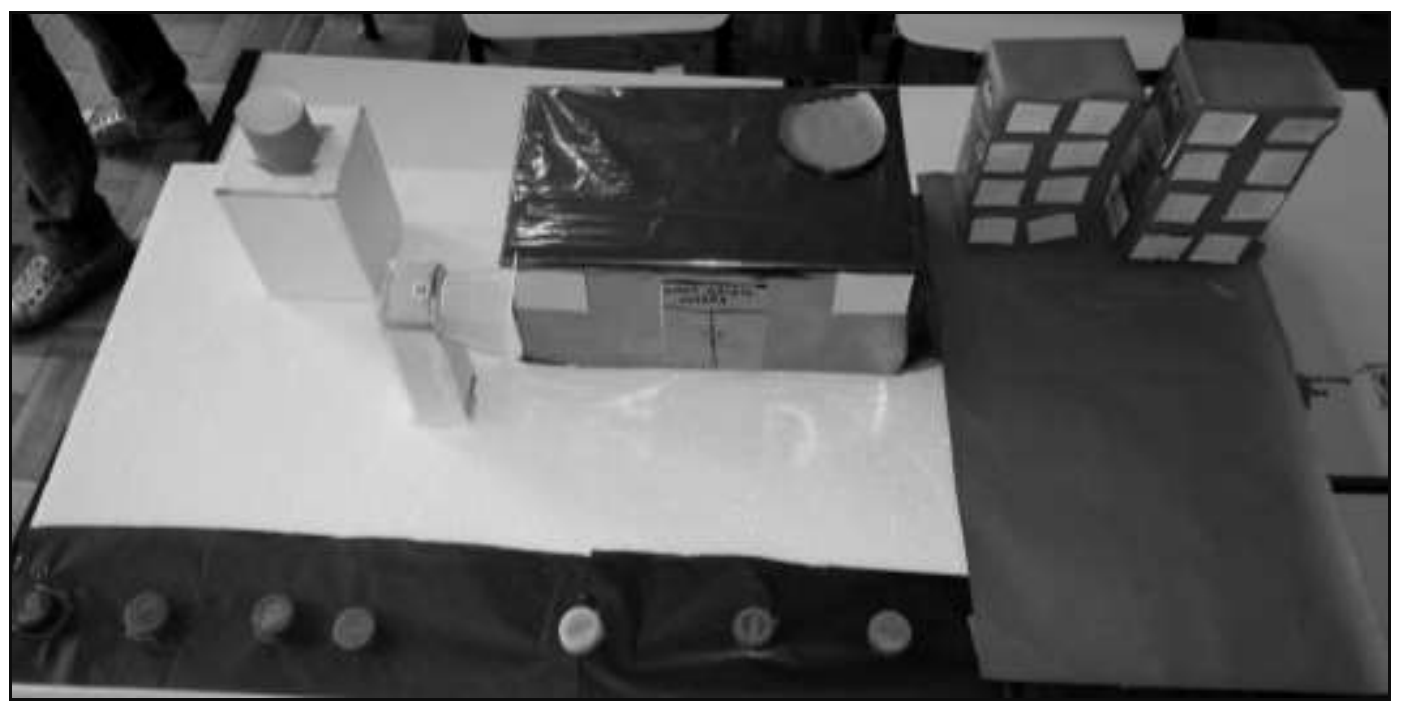

FIGURA 2 - Imagem de uma maquete com pessoas representadas pelo topo da cabeça Fonte: Pesquisa de campo 
$\mathrm{Na}$ imagem é possível perceber, do lado direito, os prédios que compõem a escola. Há do lado esquerdo uma representação da caixa d'água da escola, onde podemos observar que o grupo a estruturou sobre um prisma de base quadrangular, ainda que na realidade era de base triangular. Há a ilustração de janelas e portas. Entretanto, de modo inusitado, aparecem tampas de garrafa sobre a superfície, que corresponderiam à rua que passa em frente ao estabelecimento. A partir dessa reprodução imprevista, houve o seguinte diálogo:

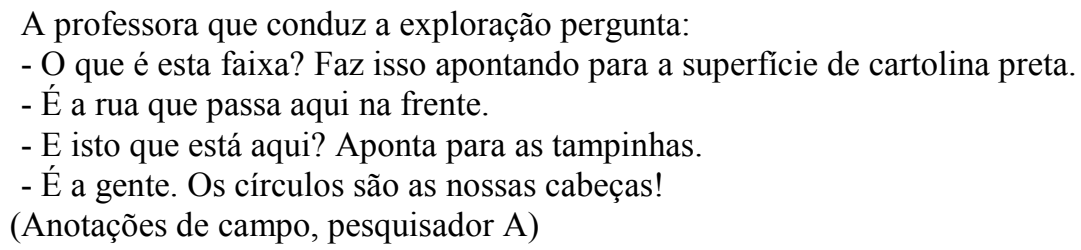

Percebemos, então, que a representação tridimensional sofreu influência de uma vista superior, mas que foi tratada de modo diferenciado. Ao imaginar um observador que sobrevoa a escola, o grupo de crianças imaginou que ele veria apenas a parte de cima da cabeça dos transeuntes e o fez a partir disso, sem representar a pessoa em si. Em outros termos, as crianças escolhem as tampinhas, ainda que um objeto tridimensional, com a intenção de representar uma vista superior bidimensional, tal como afirmam ao dizerem que os círculos são as nossas cabeças, isto é, não se referem a todo o objeto da tampinha, mas apenas a sua face superior, que tem a forma de um círculo. Nesses termos, a maquete, que é uma representação em $3 \mathrm{D}$, contém elementos que foram empregados a partir de uma referência em 2D devido à influência de uma possível vista superior. Trata-se de uma forma muito interessante de contornar as dificuldades de representar as pessoas e articular os diferentes objetos no espaço.

No mesmo sentido, outro grupo de estudantes realizou um projeto diferenciado: eles utilizaram-se de diferentes materiais recicláveis para representar os objetos tridimensionais. Todavia, ao confeccionarem os prédios, optaram por cortar as caixas de papelão que possuíam e elaborar as construções pelas paredes. A imagem a seguir evidencia a maquete construída. 


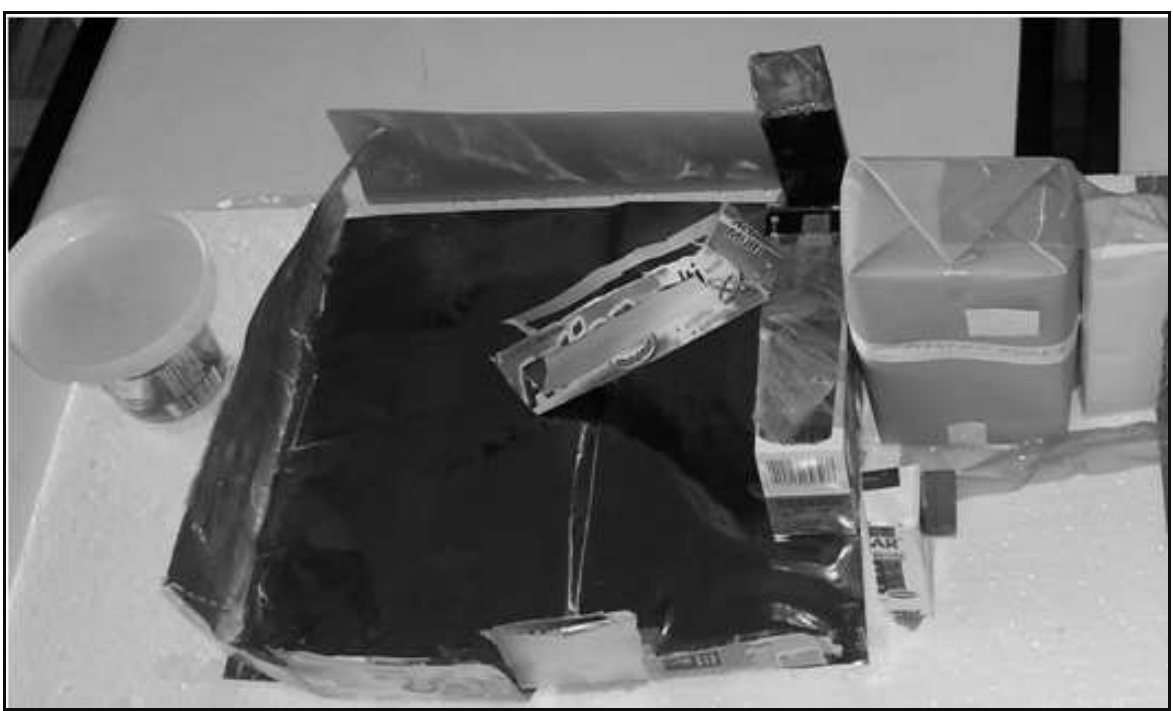

FIGURA 3 - Imagem de uma maquete

Fonte: Pesquisa de campo

Pode-se observar, portanto, que as crianças optaram por fazer alguns prédios com caixas, mas o maior deles, no qual estudam, teve erguidas as paredes. Optou-se por um modo diferenciado de representar uma figura espacial, isto é, as crianças construíram um objeto tridimensional com as faces bidimensionais que o constituem. A partir dos estudos de Piaget e Inhelder (1993), também é possível interpretar que esse grupo encontra-se em um momento do desenvolvimento no qual está privilegiando as relações projetivas dos objetos, destacando seus elementos, ângulos e figuras planas, em detrimento de relações tridimensionais já acabadas.

O diálogo a seguir ilustra como uma das crianças explica a construção.

A professora pergunta o que é isto, apontando para peças que foram recortadas.

- É o nosso prédio.

- E por que ele está diferente dos outros?

- É porque aqui estão as paredes da nossa sala e as outras do prédio.

- E por que vocês fizeram assim?

- Porque daí dá para pôr as coisas que têm dentro do prédio.

(Anotações de campo, pesquisador B).

Observa-se, na fala transcrita, que a criança optou por realizar uma representação do prédio sem o teto, a fim de que pudesse colocar elementos em seu interior e assim os deixar visíveis. Trata-se de uma forma de suprir uma inquietação, pois os sujeitos não encontraram outra maneira de atender seu desejo de dar destaque para formas que estão em seu interior. Assim, representar o prédio sem o teto permite evidenciar objetos e formas que estão muito próximas de si e que lhes interessam chamar a atenção.

\section{CONSIDERAÇÕES FINAIS}

A partir dos dados coletados e do referencial teórico empregado, foi possível construir um entendimento sobre a competência C4 da Provinha Brasil de Alfabetização Matemática, bem como das habilidades referentes aos descritores D4.1 e D4.2. O primeiro descritor trata de relacionar representações planas de objetos tridimensionais a figuras geométricas planas. As situações com as quais as crianças foram confrontadas permitiu, em diversos momentos, 
compreender como desenvolvem essa habilidade. Ao desenharem a fachada do prédio, por exemplo, precisaram identificar as formas que poderiam ser empregadas para criar representações em um desenho bidimensional. No segundo descritor a expectativa é de que os estudantes possam associar objetos do mundo físico a representações de alguns sólidos geométricos simples. Nos momentos de produção de dados, ao trabalharem com materiais recicláveis, os participantes do estudo foram demandados a associarem as caixas, latas, tampinhas a sólidos tais como os paralelepípedos dos prédios ou os cilindros das caixas d'água.

No que tange às figuras planas e à capacidade de identificá-las, nota-se que as crianças tiveram muito acesso a esse tipo de conteúdo durante as aulas de Matemática. As professoras regentes, que integravam o grupo de pesquisa, destacaram também a ênfase na geometria plana. Assim, os estudantes não tiveram dificuldades em dizer os nomes das figuras, ainda que, em alguns casos, usassem de estratégias pessoais, tais como nomear um polígono por outro, somado a alguma especificidade que o diferenciasse e evidenciando alguns traços de um pensamento mais egocêntrico.

No que se refere a identificar as figuras planas nas faces de objetos tridimensionais existentes em situações do cotidiano, os desenhos das crianças demonstram que não há maiores dificuldades para representar os quadriláteros, mas que um problema adicional pode surgir com objetos que contenham faces em forma de triângulo ou círculo. É o caso de um cilindro ou de um prisma triangular, cujas faces são compostas por polígonos de naturezas diferentes. Nota-se, assim, a produção de estratégias diferenciadas para o estabelecimento de relações bidimensionais e tridimensionais.

Nos desenhos analisados foi possível perceber a influência de um ponto de vista superior, tal como no caso da caixa d'água. Nesse momento, o conhecimento anterior da criança acerca do objeto e sua tridimensionalidade configura-se como uma dificuldade adicional para a sua representação plana. É como se a criança não se sentisse satisfeita com o uso de figuras planas de apenas um tipo para compor o desenho, tal como se o objeto não estivesse ali corretamente expressado ou se faltassem outros polígonos. Assim, apoiados nos estudos de Piaget e Inhelder (1993), Almouloud et al. (2002) e Almouloud et al. (2004), formulamos três inferências, quais sejam: (1) o fato de a noção espacial se estruturar, inicialmente, a partir da tridimensionalidade influencia as representações planas. Dessa maneira, quando a criança se depara com um poliedro mais complexo, que envolva diferentes figuras planas em sua composição, ela agrega elementos projetivos para representá-la. (2) $\mathrm{O}$ ponto de vista e a perspectiva não são muito organizados devido a um tipo de pensamento egocêntrico (PIAGET, 1994), ainda muito centrado em uma única ideia. Assim, o pensamento infantil tem dificuldade em articular figuras planas que estejam em planos diferentes. (3) $\mathrm{O}$ uso de elementos bidimensionais para representar objetos 3D são, eventualmente, um obstáculo ao pensamento infantil, de forma que são entendidos como uma vista superior de um objeto.

No que diz respeito às figuras espaciais, um fato análogo acontece: o caso das pessoas que são imaginadas como círculos e representadas por tampas de garrafa. A partir do diálogo com as crianças, nota-se que a dificuldade de representar uma pessoa e toda a complexidade do corpo humano faz com que ela procure um outro modo de expressar-se. E ainda a altura dos prédios e de outros elementos da maquete influenciam o tamanho pelo qual se deve representar um ser humano. Nesse sentido, há uma incipiente preocupação com a perspectiva dos elementos e sua proporcionalidade que, todavia, é sanada de um modo relativamente equivocado: o sujeito escolhe um objeto inspirado em uma possível vista superior e em uma \begin{tabular}{l|l|l|l|l|l|l} 
(C) ETD -Educ. Temat. Digit. & Campinas, SP & v.18 & n.2 & p.313-331 & abr./jun.2016 & ISSN 1676-2592
\end{tabular} 
representação bidimensional. No mesmo viés, as maquetes que são construídas de paredes, sem o uso de um poliedro, ocupam-se de um ponto de vista que mistura aspectos projetivos e topológicos, a fim de atender os desejos infantis de ter o prédio e de representar os objetos interiores.

A partir de tais considerações, entendemos que as crianças possuem relativa desenvoltura e bom desempenho para lidar com a competência. Reconhecer as representações de figuras geométricas. As estratégias pessoais e os modos de proceder evidenciam que, diante de uma dificuldade ou adversidade, elas procuram formas de representação próprias de outra perspectiva dimensional. Elas desenham sob outro ponto de vista ou usando recursos de outras dimensões para superarem os problemas que surgem. Mobilizam recursos que possuem e empregam combinações de figuras em desenhos planos, bem como usam polígonos em representações tridimensionais. Assim, entende-se que as diferentes formas de representação do espaço são apresentadas para as crianças, principalmente as figuras planas, mesclando-se com seus próprios conhecimentos, os quais são oriundos da experiência prática e, por isso, sobretudo, tridimensionais. Isso tudo gera uma mobilidade que usa formas de ambas as dimensões, mas que dificulta a diferenciação entre uma e outra nos processos de representação.

\section{REFERÊNCIAS}

ALMOULOUD, Saddo Agg; MANRIQUE, Ana Lúcia; SILVA, Maria José Ferreira da, et al. A geometria no ensino fundamental: reflexões sobre uma experiência de formação envolvendo professores e alunos. Revista Brasileira de Educação, Rio de Janeiro, RJ, v. 27, p. 94-108. set./dez. 2004. Disponível em: <http://goo.gl/6y9pHe>. Acesso em: 08 jun. 2015. ISSN 1809-449X.

ALMOULOUD, Saddo Agg; MANRIQUE, Ana Lúcia; GOUVÊA, Filomena Aparecida Teixeira. Análise da prática pedagógica em geometria: o ponto de vista do aluno do ensino fundamental. Contrapontos, Itajaí, SC, v. 02, n. 03, p. 325-341. set./dez. 2002. Disponível em: < http://goo.gl/IGwbeS $>$. Acesso em: 08 jun. 2015. ISSN 1984-7114.

BECKER, Fernando. A epistemologia do professor de matemática. Petrópolis: Vozes, 2012.

BRASIL. Parâmetros Curriculares Nacionais. Brasília: Senado Federal, 1997.

CARRAHER, Terezinha Nunes; CARRAHER, David William; SCHLIEMANN, Ana Lúcia Dias. Na vida dez, na escola zero. São Paulo: Cortez, 2006.

CARR, Wilfred; KEMMIS, Stephen. Teoría crítica de la enseñanza: la investigaciónacción en la formación del profesorado. Barcelona: Martinez Roca, 1988.

KEMMIS, Stephen; MACTAGGART, Robin. Cómo planificar la investigaciónacción. Barcelona: Laertes, 1988.

LAMONATO, Maiza; PASSOS, Cármen Lúcia Brancaglion. Aprendizagens de professoras da educação infantil: possibilidades a partir da exploração-investigação em geometria.

Ciências \& Cognição - Revista Interdisciplinar de Estudos da Cognição, v. 14, n. 02, p. \begin{tabular}{l|l|l|l|l|l|l} 
(C) ETD -Educ. Temat. Digit. & Campinas, SP & v.18 & n.2 & p.313-331 & abr./jun.2016 & ISSN 1676-2592
\end{tabular} 


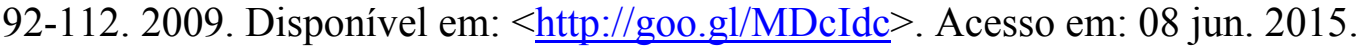

ISSN 1806-5821.

MEIRIEU, Philippe. Aprender... sim, mas como? 7. ed. Porto Alegre: Artmed, 1998.

MACEDO, Lino de. Situação-problema: forma e recurso de avaliação, desenvolvimento de competências e aprendizagem escolar. In: PERRENOUD, Philippe, THURLER, Monica Gather; MACEDO, Lino, et al. As competências para ensinar no século XXI: a formação dos professores e o desafio da avaliação. Porto Alegre: Artmed, 2002.

NACARATO, Adair Mendes; PASSOS, Cármen Lúcia Brancaglion. A geometria nas séries iniciais: uma análise sob a perspectiva da prática pedagógica e da formação de professores. São Carlos: EDUFSCar, 2003. 151 p.

OLIVEIRA, Lívia de. A construção do espaço, segundo Jean Piaget. Sociedade \& Natureza, Uberlândia, MG, v. 17, n. 33, p. 105-117. dez. 2005. Disponível em: $<$ http://goo.gl/JK8y5d $>$. Acesso em: 08 jun. 2015. ISSN 1982-4513.

PAIS, Luiz Carlos. Traços históricos do ensino da aritmética nas últimas décadas do século XIX: livros didáticos escritos por José Theodoro de Souza Lobo. Revista Brasileira de História da Matemática, Rio Claro, SP, v. 10, n. 20, p. 127-146, out./2010 - mar./2011.

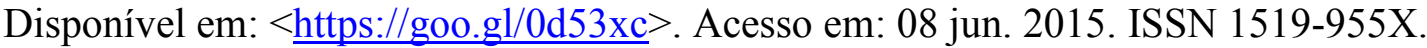

PASSOS, Cármen Lúcia Brancaglion; NACARATO, Adair Mendes. O ensino de geometria no ciclo de alfabetização: um olhar a partir da provinha Brasil. EMP - Educação Matemática Pesquisa, São Paulo, SP, v. 16, n. 04, p. 1147-1168. 2014. Disponível em: $<$ http://goo.gl/WNYbbM>. Acesso em: 08 jun. 2015. ISSN 1983-3156.

PERRENOUD, Philippe. Dez novas competências para ensinar. Porto Alegre: Artmed, 2000 .

PIAGET, Jean. O juízo moral na criança. São Paulo: Summus, 1994.

PIAGET, Jean; INHELDER, Barbel. A representação do espaço na criança. Porto Alegre: Artes Médicas, 1993.

PIAGET, Jean; SZEMINSKA, Alina. A gênese do número na criança. Rio de Janeiro: Zahar, 1981.

SILVA, João Alberto da. Escola, complexidade e construção do conhecimento. Pelotas: Editora e Gráfica Universitária, 2010.

SILVA, João Alberto da; MARINHO, Júlio Cesar Bresolin; FRANÇA, Giovanny Vinícius Araújo de. Consórcio entre pesquisas: possibilidades para o aprofundamento dos estudos qualitativos em educação. ETD - Educação Temática Digital, Campinas,

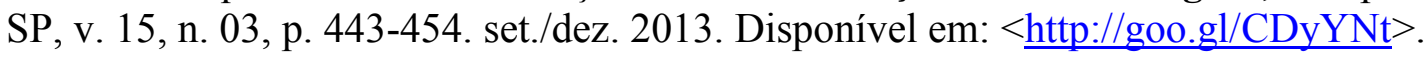
Acesso em: 08 jun. 2015. ISSN 1676-2592.

SILVA, Joao Alberto da; JELINEK, Karin; BECK, Vinicius. Strategies and procedures 
in literacy cycle children in problem situations involving informantion processing.

International Journal for Research in Mathematics Education, v. 5, p. 95-113, 2015.

SILVA, Joao Alberto da; CENCI, Daniele; BECK, Vinicius. Estratégias e procedimentos de crianças do ciclo de alfabetização diante de situações-problema que envolvem as ideias de número e sistema de numeração decimal. Revista Brasileira de Estudos Pedagógicos RBEP-INEP, v. 96, p. 541-560, 2015.

SILVA, João Alberto da; JELINEK, K. R. ; BECK, V. C. ; MIRANDA, P. S. ; FONSECA, W. . Estratégias e Procedimentos de Crianças do Ciclo de Alfabetização Frente à Situações-Problema que Envolvem Multiplicação e Divisão. Educação Matemática Pesquisa (Impresso), v. 17, p. 740-766, 2015.

ZABALA, Antoni. A prática educativa: como ensinar. Porto Alegre: Artmed, 2000.

\section{Como citar este documento:}

SILVA, João Alberto da; RITTER JELINEK, Karin; CARVALHO BECK, Vinicius. Estratégias e procedimentos de crianças do ciclo de alfabetização frente a situações-problemas que envolvem geometria. ETD - Educação Temática Digital, Campinas, SP, v. 18, n. 2, abr./jun. 2016. ISSN 1676-2592. Disponível em: 〈http://periodicos.sbu.unicamp.br/ojs/index.php/etd/article/view/8635740 >. Acesso em: 04 jul. 2016. doi:http://dx.doi.org/10.20396/etd.v18i2.8635740. 